\title{
Caminhando e falando com Vitali H. Ferera
}

\author{
Walking and talking with Vitali H. Ferera
}

Moacir Amâncio

\begin{abstract}
Resumo: Ator e contador de histórias apresenta seu primeiro livro em prosa. Vitali H. Ferera nasceu no ano de 1941 em Istambul, Turquia, e vive em Israel desde a juventude. Como ator, ele não escreveu sua história, mas cria um ambiente narrativo através do diálogo com uma personagem feminina que o acompanha na viagem aos cenários da infância e no presente. Estes episódios, criados na maioria em sua língua materna, o judeu espanhol, foram então, na maior parte, editados e traduzidos para o hebraico, com especialistas, e entremeados de trechos no original. $\mathrm{O}$ resultado é uma narrativa fascinante no aspecto histórico e social, refletindo a experiência sefardita pessoal e coletiva principalmente na Turquia e em Israel, e também na Argentina e na França. Numa época em que o judeu espanhol não funciona mais como instrumento essencial de comunicação, aqui o idioma ainda está presente com toda a sua vibração.
\end{abstract}

Palavras-chave: Sefaradismo. Judeu espanhol. Memória. Narrativa pessoal. Vitali H. Ferera.

\begin{abstract}
Actor and storyteller presenting his first book in prose, Vitali H. Ferera was born in 1941 in Istanbul, Turkey and is living in Israel since adolescence. Being an actor, he did not write his story but created a narrative environment by orally transmitting his it to a female character accompanying him on his journey in his childhood sites in the present. The following chapters, created mostly in his Judeo-Spanish mother tongue, were then edited and translated into Hebrew with experts form the original text. The result is a socially and historically fascinating narrative, reflecting the individual and the collective Sephardic experience mainly in Turkey and in Israel, and also in Argentina and in France. At an age when the Judio no longer functions as an essential tool of communication, it is present here at its full vibrance.
\end{abstract}

Keywords: Sephardim. Judeo-Spanish. Memory. Personal narrative. Vitali H. Ferera.

Vitali H. Ferera nasceu em Istambul, 1941, onde viveu até o início da adolescência, quando, preocupados com o futuro dos filhos, seus pais os enviaram a Israel, em viagem sem volta - a não ser para visitas. Parentes próximos já haviam seguido para lá. Ator e contador de histórias, Ferera descende de judeus hispano-portugueses que deixaram a Ibéria no correr das perseguições promovidas pela inquisição nos dois países da península, incluindo as colônias. Cresceu falando o judeu espanhol juntamente com a língua turca. O judeu espanhol, talvez seja mais conhecido hoje como ladino, por um provável equívoco, o que não muda coisa alguma, ou nenhuma.

Trata-se de material inédito, que aguarda publicação em Israel. É notável o talento do autor ao lidar com a palavra, como ator e contador de histórias. São recordações que se unificam graças ao tom narrativo que conduz a leitura pelo mosaico da memória e lhe confere possibilidades interpretativas diversas, à disposição de todo leitor e principalmente dos interessados nesse ramo do judaísmo ibérico que floresceu no Império Otomano, com um idioma próprio e tradições peculiares mesclados no ambiente de chegada. Resulta disso um 
vibrante autorretrato fragmentário, desde a infância até hoje em Israel, onde Ferera vive em Kiriat Ono, perto de Tel Aviv.

A mescla linguística não se limita ao judeu espanhol, na sua versão do Império Otomano e dos Bálcãs, confundido e generalizado como ladino (o termo designava as antigas traduções de textos judaicos sagrados para o castelhano, escrito com caracteres hebraicos, e hoje é assumido como uma espécie de código universal sefardita, inclusive no campo virtual). $\mathrm{O}$ idioma turco - admirado por Ferera até hoje, está presente junto com outros idiomas no decorrer do livro - uma realidade multilíngue tradicional que se enriquece no presente. A leitura é uma possibilidade de conhecermos um passado e a vivência atual de um ramo da cultura ibérica transplantado para o Oriente Médio, além dos seus trajetos locais e internacionais que prosseguem.

O texto hebraico, quando necessário, explica o significado de uma frase ou palavra, sem notas de rodapé, o procedimento foi mantido aqui, com o uso de parênteses ou não. Quanto à explicação de termos do judeu espanhol em hebraico, aqui evidentemente vertidos para o português, também acompanhamos o formato do texto primeiro (que traduz para o hebraico), mesmo que o significado coincida com os equivalentes da língua portuguesa. Na introdução, informa-se que Ferera, como ator, não escreve a sua história, mas apresenta uma experiência narrativa que se realiza com a enunciação oral dessa jornada de retorno à infância e à juventude, transformando-nos em seus leitores-ouvintes. O título hebraico Dibur toch-kedei halichá traduz a expressão do judeu espanhol equivalente: Kaminando $i$ avlando (Caminhando e falando). A tradução ao português foi acompanhada e autorizada pelo Autor.

\section{A caminho do telhado da sinagoga que havia na praia}

Viajamos agora pela estrada de Tekirdağ (Tekirdaa) rumo ao distrito de nascimento e infância da minha avó que nasceu nessa cidade às margens do Mar de Mármara. Ela era filha do pastor chamado Liyachonachi Ben-Suse - que não era outro senão Eliahu ben-Shoshan, o meu bisavô.

Como na maioria dos ônibus turcos, o vidro da janela do motorista estava em cacos, o que faz com que o olhar da gente fique um tanto quebrado... e em todos os sentidos a paisagem rural aqui indica a harmonia com os negócios do Liyachonachi, que ao que parece era um sujeito rico e notável na redondeza (o cara que me levou hoje ao curtume chegou a dizer que até agora esta região ainda é bastante roceira).

Eu me lembro, na minha infância, em Istambul, minha avó contava que ele contribuíra muito para a construção do telhado da sinagoga, realmente vizinha à praia, e pedia que quando crescêssemos viajássemos para Tekirdağ a fim de vê-lo.

Então agora eu viajo.

Mas pelo jeito não há nenhuma possibilidade de se ver o telhado, porque tudo... porque não sobrou lembrança nem sinal da existência judaica por aqui. Vamos ver se isso é verdade.

- E a história das melancias?

A história das melancias é ligada a isso de que todo lugar na Turquia tem uma "especialidade" conforme a cultura agrícola e o produto que o caracteriza. Por exemplo, em Istambul, seguindo-se a Balat - o bairro judaico onde nasci - na direção da zona rural, há um lugar chamado Alibeykoy. E a especialidade agrícola desse lugar é o milho. A praça central de Alibeykoy é igual às praças que constroem hoje em Israel para economizar com os semáforos. Esse tipo de praça. Há pouco me aconteceu de estar duas vezes em Alibeykoy e ver a praça ao redor da qual circulam os automóveis.

E o que se ergue em glória no meio da praça? O monumento ao milho! 
Em Alibeykoy há tempos já não existe lembrança do cultivo de milho, mas até hoje quando querem vender milho de qualidade na Turquia, cozido ou assado, gritam:

- Alibeykoy ün sütlü misir, Alibeykoy'ün sütlü misir!

"O milho cheio de leite de Alibei Qoi, o milho cheio de leite de Alibei koy"

Cada lugar tem algo que simboliza a sua "especialidade".

Quando voltarmos a Istambul e partirmos para Rumeli Kavak, na viagem especial para turistas chamada em turco Sêfer, tropeçaremos de novo nesse assunto. O barco vai ancorar em todo tipo de Eskalas (Estações), sendo que uma delas é a Beylerbeyi - lugar um dia famoso pelo iogurte que era produzido ali. Agora ninguém mais produz iogurte por ali. Mas quando o barco ancora, imediatamente um bando de gente corre como se trouxesse iogurte de Beylerbeyi. $\mathrm{Na}$ verdade, eles tentam vender o mesmo iogurte que se pode comprar em qualquer supermercado em todo canto de Istambul.

A mesma coisa em Tekirdağ, que era conhecida pela melancia. E quando queriam dizer que alguém era Tekirdağli (nascido lá), chamavam-no Tekirdağ Karpuzu (melancia de Tekirdağ).

Minha avó Rebeka, da qual debochavam chamando-a de melancia de Tekirdağ, também era mulher hiperativa (pode ser que eu tenha herdado dela essa marca...) e quando queríamos caçoar da sua atividade e da falta de sossego dela dizíamos:

- Tu, Tekirdağ karpuzu. Tu no te vas a trokar!

- Tu, melancia de Tekirdağ. Tu não vais mudar."

Ela se levantava todo dia às quatro da manhã. Um dia começava a cozinhar - tarefa que não terminava até a hora do almoço, pois havia em casa oito bocas para serem alimentadas... Outro dia começava a lavar a roupa dos oito membros da família. E isso de lavar não era só mergulhar a roupa em água e sabão. Antes era preciso ferver todo aquele monte de sujeira. Especialmente delas ridas yenas de gargajos ke se echavan a eyas (Especialmente os lenços cheios do catarro que deixavam nelas.) Depois da fervura eram lavadas as roupas na cozinha como os indianos no Ganges, e no dia seguinte dobrá-las e passar aquelas que não bastavam ser dobradas.

Então essas eram as melancias de Tekirdağ. Ainda agora, como lhe contei, alguém que me hospedou disse que a especialidade de Tekirdağ eram principalmente as cerejas (embora fosse o mês do Jejum de Ramadã, ele me honrava com água de cerejas), nada muda a tradição, mas o que eu tenho a dizer sobre Tekirdağ é que o lugar está ligado às melancias! ${ }^{1}$

\section{Chegar também é alguma coisa}

Lembrei agora que ultimamente retorna e se apresenta na minha vida, após longa

interrupção, um primo de segundo grau, da parte búlgara da família da minha avó Rebeka, que é a avó de Tekirdağ, e todos os seus rebentos são Tekirdaalis (originários de Tekirdağ) como ela, todos os que pertencem a esse ramo búlgaro são descendentes do Tio Meir, o Tekirdağli.

Mas eles em determinado nível se envolveram com o movimento do Barão Hirsch e a maioria deles emigrou de Tekirdağ para a Argentina um atrás do outro. ${ }^{2}$

Essa história de Argentina aconteceu por etapas. Primeiro viajou uma das irmãs, que pelo visto era ainda mais filha da mãe do que a minha avó, e começou a fazer negócios e a chamar mais um irmão, e mais um irmão e mais um irmão para se juntar a ela. Mas ela era uma

\footnotetext{
${ }^{1}$ Mês do calendário religioso muçulmano, quando é realizado um jejum diário.

${ }^{2}$ O barão Hirsch (1831-1896), banqueiro e ativista comunitário judeu patrocinou o estabelecimento de judeus na Argentina e no Rio Grande do Sul.
} 
exploradora. E a certa altura os irmãos, que começaram a trabalhar com ela, familiarizaram-se com o seu jeito (como se diz, caiu-lhes a ficha) e dois deles retornaram como tinham vindo. Um dos dois, que ainda não tinha conseguido a cidadania argentina, conseguiu entrar na Turquia. Mas quanto ao outro irmão, que já se tornara cidadão argentino, o governo não permitiu a entrada no país. Ele rolou para o Egito, esteve na Grécia e de lá chegou finalmente à Bulgária.

E esse meu primo, Mairtcho, que hoje vive nos Estados Unidos e é médico aposentado, sendo neto do mesmo irmão. O que um médico aposentado faria? Ele resolveu fazer a árvore da família. Árvore genealógica. E enquanto ainda estava ocupado com aquilo por dias e noites, descobriu-me como um grande espólio, porque eu sou conhecido pelo meu interesse na família da avó. Quando lhe disse que o avô dele era de Tekirdağ, Mairtcho me contou que quando estudava medicina encontrou alguém de lá, e essa foi a primeira vez na qual ouviu o nome “Tekirdağ". Há duas semanas ele me pediu: "Quando viajares à Turquia, visite Tekirdağ e veja o que há por lá. Isso me interessa muito".

Como no poema de Kavafis, nós ainda estamos a caminho e eu não tenho noção do que poderei transmitir a ele sobre Tekirdağ, que se esvaziou dos seus judeus. ${ }^{3}$ Se tudo o que eu puder dizer a ele for "cheguei e não há nada", mesmo assim será alguma coisa.

Chegar também é alguma coisa.

\section{Paisagem com cavalos}

Realmente já viajamos ao longo da praia, mas a paisagem ainda é roceira, e quando você diz que a paisagem é bela eu me lembro das muitas vezes em que pensei sobre a cidade de Çorlu (Chorlu), e agora finalmente visitava o mar na viagem rumo à Tekirdağ da avó Rebeca. Pela experiência dos judeus da Turquia, os Chorlulus (gente de Chorlu), são considerados uns tipos de sonhadores, esses iekim potz, mas em Israel, uma vez, eu tinha na loja um operário de Chorlu que não era assim, era um capeta dos diabos. ${ }^{4}$ Ele me contou a sua história e entre outras coisas disse que crescera sem pai.

- O que aconteceu, como seu pai morreu?

- Meu pai tinha uma carroça com cavalos, ele era um mascate que vendia mercadorias pelas aldeias. O que ele vendia eu não lembro, mas um dia ele saiu com os cavalos rumo às aldeias e a carroça voltou sem ele. Pelo jeito os cavalos sabiam o caminho... conheciam as trilhas pelas quais ele ia e voltava todos os dias.

Agora você olha o mar de Mármara. Este é o Mar de Mármara, e a direção que seguimos leva até o Estreito de Dardanelos. Até Çanakkale Tchanakale), a cidade de Bienvenida Berta Aguado-mulher que se destacou pela qualidade no cantar em djudeo, e a quem eu tive o honra de conhecer e me apresentar com ela num palco. ${ }^{5}$ Agora você contempla no fim da baía as montanhas que se alteiam.

De volta à história: o que se soube é que o pai dele foi assaltado e morto numa das aldeias cujos moradores ele tinha servido por anos a fio. Os cavalos esperaram, esperaram e esperaram... O carroceiro não veio e eles voltaram a Chorlu. Todas as vezes que eu vejo aquelas aldeias eu me lembro desse homem chamado Barokas. E quem sabe? Talvez estejamos viajando agora pelos caminhos que ele percorreu.

\footnotetext{
${ }^{3}$ Konstantinos Kaváfis (1833-1933), importante poeta grego.

4 "Judeus alemães ingênuos" - referência estereotipada a judeus locais que teriam adotado o modo religioso dos judeus asquenazes falantes do iídiche, e se tornaram por imitação a imagem de pessoas ingênuas, pontuais, de boas maneiras, muito "certinhas" etc. A expressão foi levada a Israel, como se vê.

${ }^{5}$ Bienvenida Berta Aguado (1929). Cantora sefardita nascida na Turquia, mudou-se para Israel em 1979.
} 
Sim, pelos caminhos dos cavalos.

\section{A experiência do suposto armênio}

Durante esse tempo em que viajamos, eu tenho pensado sobre a família da minha avó. Já lembramos aquele irmão dela que viajou para a Argentina e não lhe permitiram entrar de volta na Turquia porque, como foi dito, ele tinha cidadania argentina e naqueles tempos dupla nacionalidade era proibida. O nome dele era El tio Mair (o tio Mair) e nenhum de nós jamais o tinha visto, a não ser em fotografia. Todas as vezes que minha avó olhava a foto ela o beijava e começava a chorar, porque ele morreu jovem, vítima de diabetes.

Sobre o tio Mair a minha avó contava uma história que me impressionou demais.

$\mathrm{Na}$ infância, quando eu chutava a barriga dela de tanta raiva e a massacrava porque ela não me deixava comer, como eu queria, mais uma fatia de pão lambuzado de creme e cheio de sal ("delícia salgada"), ela ameaçava contar tudo o que eu havia feito e dizia: "Lo ke travi yo de tu mano, no travo ni el Ermeni!" (Até o armênio que foi trucidado pelos turcos não sofreu as torturas que eu sofri das tuas mãos e dos teus pés!).

E, talvez para me acalmar, contava sobre o irmão dela, o caçula, el tio Mair.

Ela me contou que o tio Mair, na sua fuga, durante o massacre dos armênios, seguiu por uma rua e desconfiaram que ele era armênio. Começaram a persegui-lo para matar, ele fugiu daquelas perseguições e no seu aperto ele entrou num banco da Bankalar Caddesi (Avenida dos Bancos), lugar para onde a família "fizera aliá" (migrara) de Tekirdağ.

Enquanto ele se escondia no banco, chamado em turco de Osmanli Bankasi e em djudeo La Banka Otomana, tirou as calças e a cueca para mostrar a todos aqueles imbecis mortos de fome, a shuruka (o pinto) dele, a fim de provar que era circuncidado. Eu não sei se ele queria provar que era judeu ou que era muçulmano. Pois o que há no meio das pernas dos homens turcos judeus e muçulmanos é a mesma coisa. Enfim, quando ao redor entenderam que ele não podia ser armênio deixaram-no em paz, e assim ele se salvou.

Essa história me impressionou demais "Impressionou" entre aspas, sim? A descoberta de que para sobreviver a pessoa é capaz até de se despir levando todo mundo para dentro do banco. Ainda quando menino esse espetáculo já me parecia tão surrealista... agora eu acho que talvez somente Fellini poderia encená-lo. Mas acontece que o tio Mair era uma pessoa talentosa, não menos talentosa do que Fellini.

- E também um bom diretor...

E também um diretor em nada pior. Não por acaso ele na verdade criou filhos à maravilha. Ele teve quatro filhos, todos foram para Israel e um deles era igual ao pai e mais. Os netos também, um por um eram iguais ao pai e mais, entre eles há dois médicos. Um deles é aquele que se dedica à linhagem genealógica e o outro é Jojo, que cuida do meu ouvido até no meio da noite.

Hoje, quando eu conto essa história, parece-me estranho que minha avó contou a mesma coisa em detalhes ao menino pequeno que eu era... Mas num segundo pensamento eu acho que isso não é estranho. Porque em nossa família falavam sobre tudo sem nenhum tabu. Tudo era aberto em cima da mesa. Aberto como um rio. As coisas engraçadas, as tragédias, até mesmo sexo! Os nomes dos órgãos sexuais, era como se voassem pelo espaço da casa, "livres pelo bosque", especialmente nas noites de Shabat, quando minha mãe costumava lavar as crianças no meio da sala dentro da Payla (banheira).

Essa atmosfera na minha casa, onde não havia falta de respeito, desenvolveu em mim um modo divertido de me expressar, às vezes até sem freio. 


\section{Sobre o esquecimento}

Aqui na Turquia, como entre nós em Israel, colam stickers nos veículos, aqui escrevem um cartaz, um cartaz inteiro nos caminhões. Cada um segundo a sua visão de mundo. Olha, exatamente o que você fotografa agora, enquanto seguimos de ponto a ponto de ônibus rumo ao centro de Tekirdağ, nesse cartaz há a citação de algum Zalim que disse:

"Untulanlar unutanlari katiyen unutmazlar."

Quer dizer: "Os esquecidos nunca esquecerão quem esqueceu."

Sabedoria de vida completa, podemos pensar sobre ela toda a vida, escrita nas laterais do caminhão.

\section{Natasha}

Hoje nós realmente viajamos em ônibus e nos deliciamos com a sabedoria daquelas carrocerias, mas eu quero contar também algo sobre a viagem de táxi que não está propriamente ligada a Tekirdağ.

Em geral, quando eu viajo em táxis, gosto de falar com os motoristas. Assim eu sinto a pulsação da cidade. Então, antes da sua chegada encontrei um taxista e comecei a conversar com ele. Ele era muito simpático e inteligente, nem sei de onde "saiu a conversa" (o que chamamos em turco de $i$ Sohbet lakirdi, prosa puxa prosa) sobre dor nas costas e nos músculos, de que o mundo inteiro sofre.

O taxista me disse: "Você sabe que aqui há mulheres massagistas, excelentes, que fazem massagem e você esquece de tudo?! E não pense que elas são Natashas como em Aksaray (Aqsaraii). Nada de Natashas! Mulheres direitas, profissionais, que lhe aplicam tratamento sério de todo o coração!" Então, na pista das palavras dele pensei comigo: "Em vez de dizer Orospu, que é prostituta em turco, ele disse Natasha. De hoje em diante, Kada putana es Natasha (Toda prostituta é Natasha!)" Como? Perguntei!

- Como no mundo inteiro surgiu um nome desses para as russas?

Sobre isso eu tenho uma história.

Antes de mais nada, em todos os grupos de imigrantes há uma saída para a prostituição, pela sobrevivência. Não há o que fazer. Na época da fundação do Estado de Israel, a esplanada de Jafa era ocupada por todos os tipos de mulheres que tinham imigrado de todas as diásporas do mundo. Entre elas, filhas de rabinos, e ainda que os pais delas não fossem grandes rabinos, suas casas eram guiadas segundo a tradição de Israel, e muito lamentavelmente kayeron em kamino negro (caíram no mau caminho). Como no caso do filme Margô, estrelado pela jovem Gila (Guila) Almagor, que hoje na certa seria chamada de Natasha!

Por causa disso mesmo, na Turquia, quando fulano desconfia que sicrano não lhe pagará o dinheiro devido, usa a expressão "Evvela burada, sonra burada" (Antes aqui, depois aqui.). Essa expressão sempre é acompanhada de um movimento de mão que indica o antes com a palma da mão, e depois o meio das pernas...

Por quê? Porque quando os russos se refugiaram na Turquia depois da revolução bolchevique, eles vieram a Istambul e, com todos as suas queixas, parte deles teve de trabalhar na prostituição. Talvez isso esteja enraizado na cultura russa, porque a palavra Bordel (casa de prostitutas), russa ao que parece, não designa nada de infame, mas sim algo que faz "parte da vida". Como entre os turcos, os mortos fazem parte da vida e portanto enterram-nos ao lado das calçadas, também as prostitutas do trotoar (nas calçadas) fazem parte da vida".

Então as prostitutas russas começaram a trabalhar. E os turcos, eshkias grandes, grandes monstros, perros ijo d'otros (filho de peixe é tubarão) vinham, mandavam bala e fugiam sem pagar. 
Quando as russas pegaram a coisa elas ainda não sabiam falar turco, mas aprenderam uma frase chave. E assim, quando o turco vinha... querendo transar, elas diziam a ele: "Evvela burada, sonra burada" e acompanhavam o dito com movimentos de mão. Apontavam o indicador da mão direita para o centro da mão esquerda e diziam "Evvela burada" - Primeiro põe o dinheiro aqui. E depois apontavam entre as pernas e acrescentavam "Sonra burada" (depois aqui). Quer dizer, antes de tudo o pagamento e depois botar aqui.

Essa é a resposta que eu tenho para a sua pergunta. Assim surgiu Natasha.

7. De tanto comer bolinho de carne frita - De tanto komer keftês

Agora quando eu vejo que por todo canto em Tekirdağ oferecem bolinhos, bolinhos e bolinhos eu entendo de onde veio o nosso costume familiar segundo o qual tudo o que minha avó nos dava para comer eram bolinhos de carne frita. E talvez não por acaso através da palavra kefitkas (bolinhos de carne frita) ecoam os "bolinhos de massa"...

Bolinhos e mais bolinhos e mais bolinhos.

De tanto comer keftês se muryeron todos em mi famiya de Artierios Skleroz.

De tanto comer bolinhos morreram todos na minha família de calcificação arterial.

Porque bolinhos que não continham litros de gordura animal não eram bolinhos. Então é um milagre que minha avó tenha morrido de problemas do coração, que meu avô tenha morrido de derrame cerebral, e assim também meu pai e minha mãe? É o que eles comiam todos os dias de suas vidas, e quando eu lhes dizia: "Ya basta de comer keftês. Bre! No es bueno!" Já comeram muitos bolinhos, então. Isso não é bom!"

A resposta era: "Tu ke entyendes? Tu sos siska!”

"Você, o que entende? Você é um palito magricela!"

Diziam-me: "E tu, isso e aquilo! O que você entende disso? Essa gordura é boa! Olha a papada (o queixo duplo)!" E, de acordo com a ideia deles, o queixo duplo era sinal de saúde.

Como eu disse, agora eu acho que tudo isso, esse assunto dos bolinhos de carne frita veio de Tekirdağ.

\section{8. À luz das memórias dela}

Quando vivíamos à luz das memórias da avó, pensávamos que a cidade Tekirdağ é uma passagem para as montanhas da treva. Muito longe, num outro mundo completamente. E pensar que ontem nós chegamos de Istambul em Tekirdağ em quarenta minutos. Menos de uma hora, no máximo... certo que viajamos durante a noite, quando as estradas estavam livres, mas na época da minha avó as estradas nunca eram bloqueadas. Na verdade não havia estradas! Vir a Tekirdağ ou de Chorlu a Istambul era coisa de dia inteiro. Ninguém fazia isso. Partir em viagem de dia inteiro naquele tempo era aventura séria.

Como, apesar de tudo, minha avó chegou a Istambul? Esse é um capítulo obscuro. Desde que eu me lembro, toda a família dela estava em Istambul. Dois irmãos que voltaram da 
Argentina, mais uma irmã e outro irmão que tinha um Kavane (café), e a história dele e da sua família é muito, muito especial. Ele era o irmão mais velho nascido daqueles mesmos mãe e pai.

Ela também tinha um irmão, que na verdade tinha outra mãe, mas era irmão em todos os sentidos. Todas as vezes em que ela falava sobre esse irmão, ela explodia em pranto. "Mi ermano Avran" (Meu irmão Avraham), ela o chamava, e esse irmão caiu no mau caminho e se tornou Kumarci o Kumarbaz (jogador). A propósito, o sufixo "baz dessa palavra é farsi e o sufixo gh-i é turco e tem raiz árabe.

Então ele era Kumarbaz ou Kumarg’i, cuja mãe morreu no parto dele.

\section{Orações judaicas e muçulmanas como uma coisa só}

Como foi dito, o irmão da minha avó que tinha um Kavane, era o irmão mais velho que nasceu do mesmo pai e da mesma mãe dela. E seu nome era Nisimachi. O Nissimachi tinha três filhas e um filho. Uma das filhas, que nasceu com o nome de Regina, quando ficou moça apaixonou-se por um rapaz turco muçulmano, que com o passar do tempo dirigiu-se ao pai dela, Nisimachi, e pediu a mão da namorada. Nisimachi, que negou com agressividade, expulsou-o da sua frente sem perdão. Ainda que ele tenha proibido a filha de continuar se encontrando com o rapaz, ela - que pelo visto gostava muitíssimo dele - desdisse o pai e ainda foi viver com o rapaz antes do casamento. Com o tempo ela se islamizou, recebeu o nome turco de Iffet e se casou com ele. Nasceram-lhes dois filhos. Menino e menina.

A partir do momento em que se casou ela foi banida pelo pai e excomungada pela família toda.

Regina, que mesmo após o casamento e depois de se tornar mãe continuou a residir na mesma vizinhança da família dela, pelo visto sofria com saudades deles e ansiava ter contato com eles. Ouvi dizerem que como um dos meios de renovar o laço com a família ela costumava enviar o filho caçula, de quatro anos, ao Kavane do pai dela para que ele amolecesse o coração ao ver o neto, e desejaria anular o veto. Mas o pai permaneceu em sua dureza. Além de não se comover, ele costumava expulsar o neto, humilhando-o, batendo nele: "Eu não te conheço!" Eu não quero ver você! Você não é meu neto! Some daqui e não me aparece mais aqui!"

Fiquei sabendo de todos esses detalhes quando rastreamos, Maircho e eu, as gerações da família e montamos a árvore genealógica. Esclareceu-se que a filha de Regina partira deste mundo ainda muito pequena . Quanto ao filho, que era mais moço do que a filha e se chamava Cemallettin (Gemallettin), acabou se tornando oficial com a patente de coronel no exército turco.

Quando era um jovem oficial no posto de tenente, enviou cartas e fotografias às tias dele, que já viviam em Israel, expressando sua vontade de estabelecer vínculos com elas. Mas elas também permaneciam na sua revolta. Nem chegaram a lhe responder.

Ao saber de todos esses detalhes, decidi no meu coração encontrar Cemallettin. Mas para não prejudicar a sua posição militar eu não quis, durante as minhas buscas atrás dele, revelar a ninguém que a causa da vontade de encontrá-lo era o fato de sua mãe ser judia. Minhas buscas discretas levaram oito anos sem sucesso, até que um amigo da minha família, grande especialista em Facebook, localizou todos os detalhes, inclusive suas funções no exército. Eu, que não queria me conectar com ele pelo Facebook, pois talvez os detalhes que me interessavam revelassem a todos seus amigos da mídia, que de algum modo eu havia conseguido o número do telefone dele e começara a procurá-lo por esse meio. 
A primeira conversa telefônica entre nós, que começou com sondagens muito discretas, transformou-se em grande emoção da parte do Cemallettin. A primeira frase que ele me disse, quando se convenceu de que falava com um autêntico membro da família dele, foi: "Quanta pena que mamãe não esteja viva e não veja que finalmente alguém da família se interessou por ela!"

Acontece que a mãe dele lhe contou e ele sabia de todos os detalhes dos detalhes da história da família dele, que toda ela tinha emigrado para Israel. Ele sabia os nomes deles, e me perguntou sobre todos, um por um. Combinamos que permaneceríamos em contato e garantimos que a gente falaria pelo telefone com frequência.

Somente quase dois anos depois que estabelecemos o contato, eu fui a Istambul e ele me esperava na companhia do seu cunhado fora do aeroporto e me recebeu com uma alegria sem medida. Passamos juntos aquele dia inteiro, e no correr das horas ele me contou que na verdade ele não é turco. Ele é imenita! Gerações e gerações atrás, parece que na época em que o império otomano dominava o Oriente Médio, seus tataravós emigraram do Iêmen para a Turquia. E ele na verdade parecia um "verdadeiro iemenita"...

No fim desse dia, antes de nos despedirmos, combinamos que quando eu me encontrasse na Turquia de novo, iríamos ao túmulo da mãe dele e pediríamos pela sua alma em oração segundo o estilo dos judeus e o estilo dos muçulmanos, como se fossem um só.

Desde então não me encontrei com Cemallettin para cumprirmos a promessa mútua.

\section{Coincidência}

Nós nos achamos agora à entrada de uma casa destruída em Tekirdağ que, segundo testemunho do Lokantadji (dono do restaurante) que nos acompanhou até aqui vindo do restaurante dos bolinhos de carne frita, é óbvio que no passado os judeus viveram neste lugar. Agora vemos somente paredes. E abandono.

Passeamos pelo bairro dos judeus, mas não há nenhum sinal disso.

Você não faz ideia de onde a gente vai! A minha Nona (a avó) sempre usou a expressão Üzüm bagi, montagem de üzüm (uvas), e Bag (vinhedo-parreira). E olhe que esta casa destruída tem dentro dela uma parreira que avança para fora e a cobre quase toda. Que bonito, realmente! Olhe, fotografe isso deste ponto. Sim, sim, muito bom. Por favor, fotografe assim. Olhe o que você vai ver, olhe! Fotografe, Presiada (querida), fotografe para Maircho!

Um dos meus sonhos em relação à Turquia era vir e rastrear as raízes da Gran-mamá Rebeka (avó Rebeca), vivenciar o lugar no qual se passou a juventude dela e sobre o qual ela contava todos os tipos de histórias. E aqui está, de modo algum é possível dizer que por obra do acaso chegamos ao Yahudi mahallesi (bairro dos judeus) em Tekirdağ. Imagine por si própria que em vez de chegarmos aqui de ônibus e a pé, tivéssemos vindo de táxi e o motorista nos levaria aonde fosse. Ou que não tivéssemos estado naquele restaurante nem no bairro judaico onde, por acaso, mora o dono. Eu estou cheio de ocorrências do acaso que envolvem toda a nossa estadia em Tekirdağ.

Se existe prova de que não há coincidência no mundo, esta é a coincidência de hoje.

Sob a influência do entusiasmo da coincidência, enquanto estava em Tekirdağ falei ao telefone com Maircho, que como foi dito é o fiel depositário da nossa documentação genealógica e familiar, contando-lhe tudo o que me aconteceu aqui. Eu tenho esperança de que no ano que vem, na sua viagem para a reunião periódica com seus companheiros em Israel, consigamos visitar juntos este lugar aqui e então rastrearemos os arquivos que se encontram com Mehmet Seres - o autor que pelo visto documenta todos os fatos de Tekirdağ (e que pelo visto ele é da cidade de Seres, ao norte de Kavala, na Grécia, que não é distante desta região e tive a honra de visitar na minha viagem a Salônica. Maircho foi quem me deu a ideia de procurar 
o número de telefone dele, e assim o fiz. Perguntei a muitas pessoas, mas não o encontrei. Vamos viver para ver o que sai de tudo isso.

Bom, agora já está escuro e também começa a cair uma chuva torrencial na estrada de terceiro mundo.

\section{Casa da Vida}

Como foi dito, meu sonho de vir a Tekirdağ originou-se do pedido da gran

mama da minha mãe, Rebeka, que eu viesse até aqui para uma visita e visse a sinagoga cuja cobertura foi doada pelo pai dela, Liyachonachi, Çoban (pastor). Sempre sonhei em realizar o pedido dela, mas ouvia que toda esta área judaica já não existia mais. O que se esclareceu é que a sinagoga, que, pelo que me disseram, era vizinha à praia, tem o seu lugar localizado hoje em terra firme, pois o mar foi drenado e sobre ele pavimentou-se uma estrada, e também um calçadão e por ele seguimos realmente ao longo do limite do mar. Então eu suponho que a sinagoga ficava perto do bairro judeu, na área que agora está em terra firme.

Quando nos encontrarmos, se nos encontrarmos, se Deus quiser, com esse Mehmet Seres sobre o qual me disseram, documentou toda a história de Tekirdağ em suas gerações, sobre os judeus e demais grupos étnicos, talvez ele possa nos dizer exatamente onde se localiza, ou onde se localizava a sinagoga.

Do calçadão às margens do mar, na companhia do proprietário do restaurante ou do sujeito que trabalha lá, subimos até o bairro dos judeus e vimos as casas cuja beleza dos tempos passados ainda é considerável, mas elas estão bastante arruinadas. Casas das quais às vezes vêse apenas a fachada, ou uma parede interna. Há entre elas casas que se encontram apodrecidas, porque foram todas feitas de madeira, e a madeira se deteriorou. Elas são definidas como construções de preservação, sendo proibido destruí-las, e à medida que pretendem reformar aquelas casas, é preciso construí-las exatamente como eram.

Mas na sua desolação elas são muito mais bonitas do que se fossem reconstituídas.

No trajeto entre aquelas casas caímos dentro de uma pitaria. Agora é o mês do Ramadã, quando na Turquia preparam pitas especiais, besuntadas em gema de ovo, para quebrar o jejum. Todos os padeiros eram curdos da cidade de Urfa e quando ouviram que nós éramos judeus disseram: "Nós viemos do mesmo pai, somos da mesma estirpe". E na verdade foi provado cientificamente que a estirpe mais próxima dos judeus é a estirpe dos curdos. Os padeiros nos convidaram para entrar, serviram chá para nós, explicaram toda a história deles na Turquia. Durante a nossa passagem com eles recebemos um telefonema de Maircho e lhe contei tudo o que acontecera.

Mairtcho perguntou se havia um cemitério aqui, apelidado de Bedjudeo Bedahaim (Casa da Vida), e eu lhe respondi que sim. Porque eu me lembrei que o homem no restaurante, que testemunhou ter crescido entre os judeus e contou que até seis-sete anos atrás havia judeus aqui em Tekirdağ, dissera que o cemitério judaico estava conservado à maravilha.

Chegamos ao cemitério e para nosso espanto esclareceu-se que o cemitério está arruinado à maravilha, com as lápides espalhadas por todo lado, até o ponto em que não é possível saber se elas ainda cobrem mesmo os túmulos que lhes pertencem. Fotografamos três ou quatro lápides, sobre uma delas estava escrito que era a lápide de uma virgem bela e bonita, em outra lápide estava escrito sobre um homem grande e culto. Certo, certo, muito instruído.

E a dor no coração de ver um cemitério arruinado.

É isso. Agora estamos a caminho de Chorlu. A mesma cidade que aos olhos dos demais judeus da Turquia, os judeus dali eram um tipo de sonhadores. Mas eu não acredito nisso. Eles, provavelmente, eram mais sábios do que os judeus de outras cidades, que não tiveram sucesso diante deles e então os apelidaram de sonhadores... chorlulus! 


\section{A gripe aviária}

Bom, agora eu ainda quero contar algo que não pertence a Tekirdağ. Um ou dois dias antes de sair para este passeio misturado com trabalho, business \& pleasure, ouvi nas notícias que na Turquia se espalhara a gripe aviária e pelo que previam, a sua dimensão era comparada à dimensão da gripe asiática, da gripe espanhola, que castigou a Espanha há... quantos anos atrás?

Pela vida de minha mãe, que agora deveria ter mais de noventa anos, quando ela tinha dois anos, mais ou menos, a Espanha foi atacada pela gripe espanhola que deixou milhões de vítimas. Entre elas também estava o homem a partir do qual fui chamado de Vitali, que era o meu avô materno Vitali Gershon (Guershon).

Quando ouvi as notícias sobre a gripe aviária chamada aqui de Kus gribi, (a gripe das aves), pensei em como seria interessante se no correr da minha passagem pela Turquia ela me atacasse e também eu morresse de gripe segundo as proporções espanholas.

Talvez seja mesmo um fechamento de ciclo - da expulsão da Espanha à Turquia, pela da gripe... 